\title{
Crisis financiera internacional y sus efectos en la economía mexicana*
}

\author{
Juan Carlos Moreno-Brid** e Igor Paunovic***
}

\section{RESUMEN}

El artículo examina las razones por las que la economía mexicana es una de las más gravemente afectadas por la crisis financiera internacional. Para ello identifica los canales principales de transmisión de sus efectos de la crisis internacional y de qué forma inciden en las fortalezas y vulnerabilidades principales de la economía mexicana. En el análisis que se hace de las respuestas de política económica que se han adoptado (hasta mediados del 2009) se subrayan los retos decisivos que se enfrenta en este terreno para conciliar diferentes objetivos: aminorar urgentemente los impactos negativos de corto plazo en la población vulnerable, corregir características estructurales que limitan las perspectivas de crecimiento de largo plazo de la economía, y poner en marcha una política macroeconómica contracíclica, manteniendo a la vez las finanzas públicas en una senda sustentable.

Palabras clave: México, desarrollo económico, crecimiento, reformas macroeconómicas. Clasificación JEL: O11, 054.

\begin{abstract}
The paper examines the reasons why the Mexican economy is one of the most severely affected by global financial crisis. This identifies the main channels of transmission of the effects of international crises that affect how the main strengths and vulnerabilities of the Mexican economy. The analysis is made of the economic policy responses that have been adopted, to date, mid 2009 - highlights the key challenges faced in this area to reconcile different objectives: minimize the negative impacts of urgent short-term in vulnerable populations, correcting structural features that limit the prospects for long-term growth of the economy, and implement countercyclical macroeconomic policy while maintaining public finances on a sustainable path.
\end{abstract}

Key words: Mexico, economic development, growth, macroeconomic reforms. Classification JEL: O11, 054.

* Las opiniones expresadas en el presente ensayo son responsabilidad exclusiva de los autores y no necesariamente coinciden con las de la CEPAL o la Organización de las Naciones Unidas. Este artículo es una versión revisada y actualizada de la presentación hecha por los autores en el Seminario Internacional "Crecimiento económico y desarrollo en América Latina", organizado por la UAM en marzo 2009, y en parte se basa en el artículo publicado por J. C. Moreno-Brid en Nueva Sociedad, núm. 220, marzo-abril 2009. Elaborado en julio de 2009.

** Coordinador de investigación, sede subregional en México, de la Comisión Económica para América Latina y el Caribe (CEPAL).

*** Jefe de la Unidad de Desarrollo Económico, sede subregional en México, de la CEPAL. 


\section{INTRODUCCIÓN}

La economía mundial atraviesa la coyuntura más desfavorable que ha enfrentado desde la Gran Depresión de los años treinta. Su origen inmediato data del colapso del mercado hipotecario de Estados Unidos (EUA) en un marco de agudos desequilibrios estructurales en ese país tanto fiscales como de balanza de pagos. De entonces, el escenario económico ha estado marcado por la quiebra de múltiples instituciones financieras, además de caídas bruscas de la producción y el comercio, así como por el colapso de mercados crediticios y bursátiles. Con el cierre de grandes empresas industriales - y un sinnúmero de pequeñas y medianas-, hay consenso de que en 2009 el comercio y la producción mundiales tendrán una contracción en términos reales.

Todas las naciones - tanto del mundo industrializado como en vías de desarrollo - resienten los efectos de la crisis financiera internacional, ya desde el último trimestre de 2008, en sus niveles de producción, inversión, comercio y empleo. En general, las economías emergentes viven una contracción o desaceleración brusca de su actividad productiva y su ocupación formal (Banxico, 2009). Los organismos financieros internacionales y centros de análisis coinciden en que este adverso entorno económico global que persistirá durante 2009 y comience, quizá, una gradual y modesta recuperación en la segunda parte de 2010. Tales estimaciones están sujetas a gran incertidumbre. Dependen de los efectos que tenga, sobre todo, la estrategia puesta en marcha por el gobierno de Estados Unidos y por los diversos gobiernos nacionales. ¿En qué medida los gobiernos de la región — incluyendo el de México - serán capaces de instrumentar políticas anticíclicas y que tenga un impacto significativo?

La crisis actual está teniendo un efecto adverso de diferente magnitud en las distintas regiones del mundo. Si bien Asia es de las zonas más afectadas, América Latina acusa una desaceleración considerable. En la región, México está siendo una de las economías más afectadas dadas sus estrechas ligas comerciales y encadenamientos productivos con los Estados Unidos. De hecho, en julio de 2009, México registró la más grave contracción anualizada del PIB real en toda la región. Esta caída ha llevado a diversos analistas a sugerir que para el cierre del año la reducción del PIB bien puede superar $6 \%$ y ubicarse cerca de $8 \%$. El índice de confianza del consumidor ha bajado con fuerza, a la vez que el desempleo abierto supera $5 \%$, su máximo en muchos años, con una pérdida acumulada de afiliados al IMSS aproximada de más de 800 mil trabajadores desde octubre de 2008. 
Las proyecciones recientes de la Secretaría de Hacienda y Crédito Público de México estiman que en 2009 la economía mexicana caerá cerca de 6\%. La OCDE, por su parte, considera que la caída puede ser unos puntos mayor, con una severa contracción laboral. En todo caso, dada la incertidumbre en cuanto a la duración y profundidad de la recesión mundial, nos parece más conveniente concentrar el presente texto en examinar aspectos de naturaleza más estructural, de más largo plazo: $i$ ) ¿por qué canales se transmiten los principales efectos de la crisis internacional hacia la economía mexicana?, ii) ¿cuáles son las fortalezas y vulnerabilidades principales de la economía mexicana ante la crisis?, y iii) ¿cuáles son los retos, avances y pendientes de la respuesta de política económica del gobierno frente a la crisis internacional para aminorar los impactos negativos de corto plazo y, a la vez, ayudar a insertar la economía mexicana en una senda de elevado crecimiento de largo plazo? Las siguientes partes de este artículo abordan estas cuestiones.

\section{FORTALEZAS Y FRAGILIDADES DE LA ECONOMÍA MEXICANA AL INICIO DEL SIGLO XXI}

\section{Antecedentes: la reforma neoliberal}

Como es conocido, la estructura actual de la economía mexicana es en gran medida resultado del proceso intenso de reformas emprendido desde mediados de los ochenta para colocar las exportaciones y la inversión privada como motores de expansión de la economía nacional. Dichas reformas, ampliadas por administraciones subsiguientes, convirtieron a México en una de las economías de tamaño medio más abiertas al comercio y a la inversión internacional en el mundo, y redujeron fuertemente el ámbito de injerencia del sector público en la inversión y la producción.

Las reformas abordaron tres grandes ámbitos. El primero, urgente, fue el de enfrentar la tarea de abatir la elevada inflación y corregir el déficit fiscal. Dicha estabilización fue conseguida desde fines de los ochenta en parte por el recorte del gasto público y en parte por la aplicación de un programa de estabilización heterodoxo — el Pacto de Solidaridad Económica - suscrito por los sectores empresarial, laboral y gubernamental. Los acuerdos sectoriales de entonces abarcaron el control de la evolución del tipo de cambio, del salario mínimo nominal y de los precios de algunos bienes básicos. 
En los otros dos ámbitos, las reformas transformaron la estructura económica del país. Se abrieron los mercados locales a la competencia externa al eliminar el sistema de protección basado en una gama de permisos, controles y múltiples aranceles. Y se redujo drásticamente la intervención del sector público en la esfera económica.

\section{a) Apertura al comercio y a la inversión extranjera}

La eliminación del régimen proteccionista procedió con la firma de acuerdos internacionales proclives al libre comercio, en especial la adhesión al GATT en 1986. Siguió con el desmantelamiento unilateral del sistema de protección comercial, ${ }^{1}$ desde mediados de los ochenta, inicialmente de manera gradual y luego aceleradamente. Y culminó con la firma del Tratado de Libre Comercio de América del Norte (TLCAN) con Canadá y Estados Unidos. Éste comenzó a operar el primero de enero de 1994 con el fin de eliminar prácticamente todas las barreras arancelarias y no arancelarias al comercio y a la inversión intrarregional en un plazo no mayor a 15 años. Desde entonces, México ha firmado más acuerdos de libre comercio, inter alia, con Chile, Costa Rica, Colombia, Venezuela, Bolivia y la Unión Europea. En este ámbito, cabe destacar también la adscripción del país a la OCDE y a la Organización Mundial de Comercio. El TLCAN incorporó el compromiso de liberalizar los flujos de inversión extranjera y la aceptación de ciertos criterios ambientales y laborales a ser satisfechos regionalmente.

Para México, el TLCAN tuvo tres objetivos. El primero fue reducir las presiones inflacionarias en el país, permitiendo mayor competencia externa. El segundo fue insertar la economía mexicana en una trayectoria de elevado crecimiento de largo plazo impulsada por la exportación al mercado de Estados Unidos. Finalmente, el tercero fue asegurar la irreversibilidad del proceso de reformas económicas con la firma de un tratado formal con EUA en pro del libre comercio.

En cuanto a la IED, con la salvedad de la petroquímica básica — cuya cobertura fue estrechándose-, y la producción de armamentos y explosivos, la manufactura quedó del todo abierta a la inversión extranjera, incluso mayorita-

\footnotetext{
${ }^{1}$ Este sistema se componía de diversos elementos, incluyendo el requisito de permisos previos a la importación, las tarifas arancelarias y los esquemas de precios oficiales sobre algunos bienes importados o exportados.
} 
ria. La última medida significativa de apertura, adoptada posteriormente a la crisis de 1994, fue para rescatar el sistema de la banca comercial del país al autorizar la entrada de IED en el sector sin fijar tope alguno a su porcentaje de participación en el capital.

\section{b) Reducción de la intervención del sector público en la esfera económica}

La apertura comercial y a la IED produjo una disminución fuerte de la intervención del sector público en la economía. Esta disminución se acentuó con la privatización de entidades públicas y la eliminación de la política industrial. La privatización se hizo para dar mayor margen de acción al sector privado y reducir el déficit fiscal pues, salvo excepciones, las empresas desincorporadas operaban con pérdidas (Moreno-Brid y Ros, 2009).

El primer momento de la privatización se dio a mediados de los ochenta con la venta de poco más de 200 empresas medianas o chicas. El segundo, 19891996, fue la venta de empresas grandes con poder de mercado y llevó a desincorporar más de 1000 de las 1155 empresas públicas que existían en 1982. Desde entonces, ha habido una nueva ronda de ventas de empresas de servicios ferrocarrileros, administración portuaria y otros servicios. La reapertura de la discusión sobre la reforma energética en 2008-2009 no alteró este panorama y se mantiene el status quo de fuertes restricciones a la participación del sector privado en la petroquímica básica, si bien en la petroquímica secundaria contempla la posibilidad de tener hasta $100 \%$ de inversión privada, local o extranjera.

El segundo modo de acotar la participación del estado en la economía fue con el desmantelamiento de la política industrial. Se sustituyó el esquema tradicional de subsidios y fomento a sectores específicos, y se abandonó todo esquema de injerencia directa selectiva vía subsidios, permisos, licencias o condiciones de desempeño en torno a requisitos como el grado de contenido nacional o la generación neta de divisas. La nueva política de fomento se centra en promover el libre juego del mercado — sin apoyo o subsidios estatales — buscando facilitar trámites administrativos y fortalecer el respeto a los derechos de propiedad. En concordancia con las disposiciones del GATT/OMC, se dejaron en vigor sólo algunos estímulos tributarios a la importación temporal de insumos para su reexportación. Dicha política ha estado, en esencia, inalterada desde los años noventa a la fecha. 


\section{RESULTADOS DE LAS REFORMAS}

\section{Inflación y finanzas públicas}

Las reformas económicas han tenido un éxito innegable en corregir el déficit público y en lograr una plataforma de baja inflación. En efecto, con base en el recorte del gasto público, y no en el aumento de sus ingresos, el gobierno mexicano ha eliminado prácticamente los números rojos en las finanzas públicas y ha abatido su deuda externa. Cifras oficiales ubican su saldo al cierre de 2008 en 56 mil millones de dólares - monto 40\% menor al de 10 años atrás- que es equivalente a $6.1 \%$ como proporción del PIB.

Así, sin contar los pasivos contingentes asociados con el régimen de pensiones del sistema de seguridad social, desde varios años atrás el déficit público se mantiene por debajo de $2 \%$ como proporción del PIB. De hecho, en años recientes se ha vuelto norma el registro de un superávit en las finanzas públicas. Cabe subrayar que el Congreso de la Unión Aprobó la Ley Federal de Presupuesto y Responsabilidad Hacendaria (Diario Oficial, 30 de marzo de 2006) que vuelve obligatorio el mantener un balance anual equilibrado entre el gasto y el ingreso público; es decir un déficit igual a cero. Si bien en 2008 se hizo un ajuste para excluir el gasto de inversión de Pemex del cálculo del balance fiscal para tales fines, la ley federal mencionada impone una restricción notable a la conducción contracíclica de las finanzas públicas. Sólo en condiciones macroeconómicas extraordinarias, la ley da margen para solicitar autorización de tener un déficit fiscal temporal acotado del PIB.

Pero no se han podido corregir dos elementos vulnerables del presupuesto público en una perspectiva de mediano plazo. El primero es la baja carga tributaria. En efecto, su monto, inferior a un equivalente de 14\% del PIB, ubica a México entre los países con menor carga fiscal en la OCDE, y como uno de los de más baja recaudación de las economías de ingreso comparable en América Latina. El segundo es la excesiva dependencia del fisco de los recursos petroleros. Éstos representan hoy en día cerca de $40 \%$ de los ingresos fiscales totales. Dichos recursos dependen de los precios internacionales del petróleo, sujetos a fuertes fluctuaciones, y enfrentan el reto de la caída de las reservas petroleras y de la capacidad de producción del país. Ambos elementos limitan la capacidad del gobierno mexicano de realizar una política anticíclica de gran y sostenido alcance, a menos que se instrumente una reforma fiscal profunda. 
Por su parte, la inflación — después de haber alcanzado niveles anuales de tres dígitos a mediados de los años ochenta - ha mostrado una tendencia a la baja. De hecho, ya desde 2000 el alza anual del índice de precios al consumidor ha sido de sólo un dígito. En ello, ha sido decisiva la política de flotación —en la práctica y hasta el inicio de 2009 - muy acotada del tipo de cambio nominal del peso frente al dólar. Además, al menos hasta diciembre 2008, las tasas de interés seguían orientadas a abatir presiones inflacionarias.

\section{Auge exportador manufacturero}

Las reformas detonaron un auge exportador - sobre todo de manufactureras- $-\mathrm{y}$ fuerte alza de la IED. En efecto, desde la firma del TLCAN, las exportaciones manufactureras mexicanas crecieron a una tasa media anual por arriba de $10 \%$, que si bien es inferior a la de China, es una de las más altas del mundo. Tal dinamismo llevó, de 1994 a 2008, a las exportaciones a duplicar su participación en el PIB (colocándola cerca de 35\%). Agregando las importaciones, el comercio internacional se elevó a representar en promedio más de 60\% del PIB en 1994-2008, más del doble de 10 años antes. La inserción exportadora del país dejó de tener un perfil basado en los hidrocarburos y se centró en las manufacturas. Su éxito se apoyó en las maquiladoras, las plantas automotrices y las empresas extranjeras establecidas en el país, además de las atraídas por el TLCAN. Es de notar que el auge estuvo muy centrado en unas cuantas industrias, entre ellas la de motores y partes automotrices, automóviles, computación y equipo electrónico diverso.

El dinamismo exportador de México ha permitido generar un superávit comercial con los EUA, pero a la vez un crecientemente abultado déficit comercial con el resto del mundo. El superávit comercial derivado de las maquiladoras y de la industria petrolera ha sido más que cancelado por el déficit que se genera en el resto del mundo en el comercio de manufacturas, bienes primarios y servicios. La acelerada penetración de las importaciones ha limitado la capacidad de arrastre del sector exportador respecto al resto de los sectores. Con ello, el dinamismo exportador no ha dado impulso suficiente a la economía mexicana en su conjunto para permitirle insertarse en una senda de expansión elevada y sostenida. El elevado impulso de las importaciones se debe en parte a la tendencia a apreciar el tipo de cambio real y a la ruptura de unos "encadenamientos" entre proveedores y fabricantes locales, que se han visto desplazados por las importaciones. 


\section{Limitaciones del nuevo modelo: falta de arrastre exportador y de inversión}

La insuficiencia del nuevo modelo (export-led growth) para el caso mexicano se ilustra en la gráfica 1, que se asocia con el desempeño comercial y el ritmo de expansión del PIB real en los pasados 40 años. En 1970-1981, el PIB real creció a $7 \%$ medio anual y registró un déficit comercial ( $2 \%$ del PIB). La fase siguiente (1982-1987), marcada por el ajuste ante la crisis internacional de la deuda, trajo un estancamiento económico y un superávit comercial notorio ( $8 \%$ del PIB). En la primera fase de reformas previas al TLCAN, la economía creció a una tasa media anual de $3.5 \%$, la mitad de su ritmo de expansión en los setenta, y una vez más generó un déficit comercial similar al de entonces.

Gráfica. 1. Balanza comercial y crecimiento económico, 1970-2008

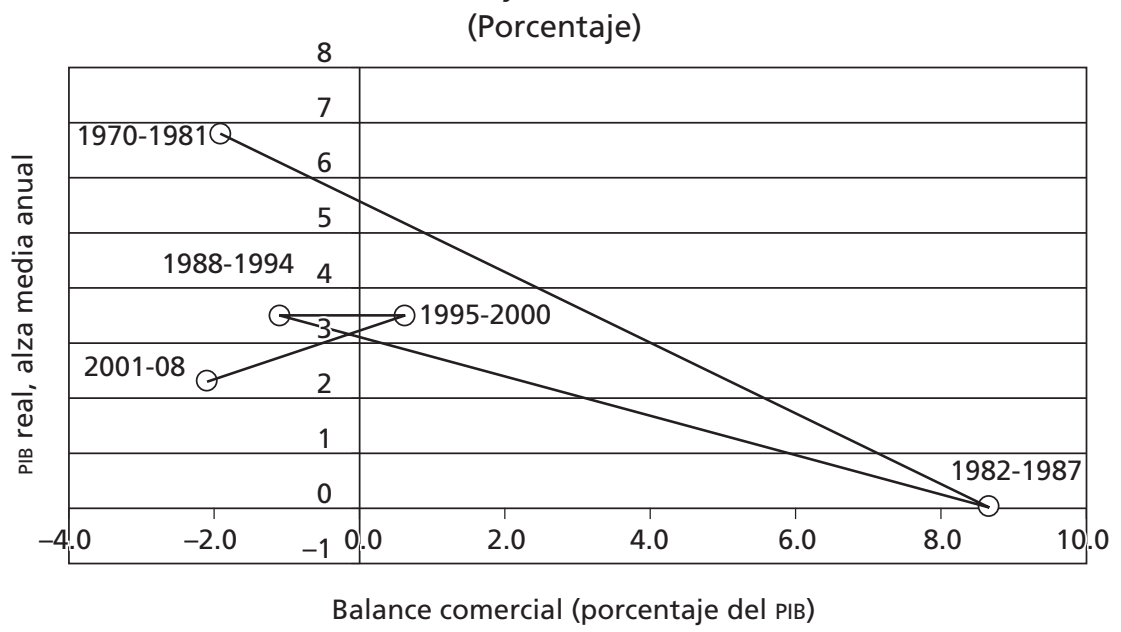

Fuente: Elaboración propia con base en datos de INEGI y Banxico.

La tasa de expansión económica y el desempeño comercial muestran una pauta similar en 1995-2000 ya con el TLCAN, afectados por la crisis de 1995 que contrajo el PIB en más de 6\%. En lo que va del presente siglo, y casi 20 años después de que se inició el proceso de reformas liberales, la economía de México padece un déficit comercial similar al de los años setenta pero creció en promedio tan sólo a una tercera parte de la velocidad de entonces. Es decir, con un uso proporcionalmente similar de divisas, la economía de México en 2000-2008 creció por debajo de sus pautas históricas, no obstante la robusta expansión de la economía mundial, el franco acceso al mercado de capitales y la mejora de tér- 
minos de intercambio. Tan bajo crecimiento de la economía impide generar suficientes puestos para absorber la expansión de la fuerza de trabajo. De acuerdo con diversas estimaciones, el PIB de México requiere crecer cuando menos a 5\% anual para crear anualmente entre 800 mil y un millón de empleos. Si además se quisiese reducir de manera significativa la pobreza - que actualmente afecta a más de $40 \%$ de la población y, en su forma extrema, la pobreza alimentaria, a poco más de $10 \%$ - la expansión económica debería ser aun mayor.

La segunda limitación aguda del nuevo modelo de desarrollo de la economía mexicana ha sido la escasa inversión. La inversión fija bruta alcanzó su cima - como proporción del PIB - en el auge petrolero, para después colapsarse ante la crisis internacional de la deuda (1982-1987). Su recuperación ha sido insuficiente y es muy baja en comparaciones internacionales. El cociente de inversión es inferior a $25 \%$ requerido para lograr tasas de expansión económica superiores al $5 \%$ anual de manera sostenida.

Tan pobre respuesta de la inversión a las reformas macroeconómicas se explica por varios factores: $i$ ) la escasez de crédito para gran parte de las empresas nacionales, ante la baja oferta de créditos bancarios para actividades productivas y el debilitamiento de la banca de desarrollo; ii) la contracción de la inversión pública a partir de las reformas estructurales impactó la infraestructura y minó la competitividad internacional; iii) la cancelación de los programas de fomento industrial deprimió la inversión privada, y iv) la persistente apreciación cambiaria tendió a canalizar la inversión privada a la producción de bienes y servicios no comerciables. En síntesis, la baja inversión frena el crecimiento económico al dificultar la ampliación y modernización de la maquinaria y el equipo. Sin ellas, el aparato productivo pierde competitividad tanto en los mercados mundiales como en los locales.

La falta de dinamismo de la economía amplía la brecha del PIB per cápita de México frente al de EUA. En efecto (véase gráfica 2), desde el fin del boom petrolero de 1982, el rezago de México se acentúa. La estabilización y el repunte económicos logrados a partir de 1987 acortaron dicha brecha, pero su avance se revirtió de manera abrupta con la crisis de 1995. Desde entonces, la brecha permanece cercana a 16\% (muy abajo de 24\% que alcanzó en 1982). Esta brecha es comparable a la registrada durante la década de los cincuenta, es decir, hace más de 50 años. Consecuencia de este rezago es el fuerte impulso de la migración a los EUA, que — según diversas estimaciones - alcanza año con año de 400 a 500 mil mexicanos. Sin esta válvula, el mercado laboral mexicano alcanzaría niveles de presión todavía más preocupantes. 
Gráfica 2. México y otros países de América Latina: PIB real por habitante en relación con EUA, 1980-2008 (PIB por habitante de EUA $=100$, dólares constantes de 2000)

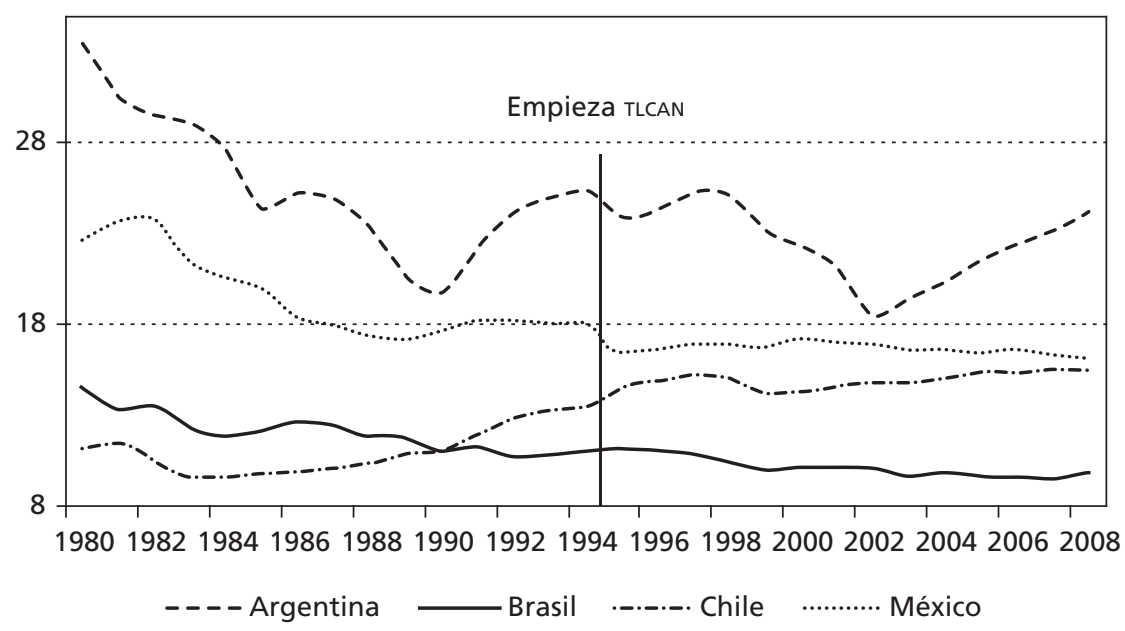

Fuente: Elaboración propia con base en datos de World Development Indicators.

\section{Transmisión de la crisis internacional a la economía mexicana}

Una primera forma en que la economía mexicana resiente los efectos desfavorables de la crisis es por el debilitamiento del comercio con EUA. La contracción de la economía estadounidense y de su demanda de exportaciones presiona a la baja los volúmenes y precios de venta de las exportaciones mexicanas. Dos sectores especialmente complicados serán el automotor —y la manufactura en generaly el del turismo. De hecho, en lo que va registrado de 2009 tuvieron contracciones anualizadas importantes (56\% en las exportaciones de autos y $10 \%$ en las ventas en el sector turístico). Si se dan tendencias proteccionistas en el mercado de EUA, o si las armadoras de autos deciden cerrar plantas en México, el efecto en la producción y el empleo puede agravarse.

Por demás importante es la evolución del mercado petrolero, dada su relevancia como fuente de ingresos fiscales y generador de divisas. El país recibió una noticia muy favorable el 17 de febrero con el anuncio del gobierno mexicano del descubrimiento y certificación de un yacimiento extraordinario de 139 mil millones de barriles en Chicontepec, que coloca a México en el tercer sitio mundial de países con mayores reservas probadas. Falta ver cómo y cuándo se explotará. En el corto plazo es importante. 
Las remesas familiares son otro elemento relevante en la dinámica económica y social del país, que se ve afectado por la recesión estadounidense. La pérdida de puestos de trabajo en los EUA mina el empleo y las remuneraciones de los trabajadores emigrados que ahí residen. La contracción del flujo de remesas familiares puede generar un problema grave en las condiciones de vida de algunas localidades y comunidades del país que dependen fuertemente de esos envíos monetarios desde el extranjero.

Otra forma en que la crisis internacional incide en la economía mexicana es en el menor acceso al financiamiento externo al país. En efecto, la restricción crediticia que se sufre en los EUA y en las economías industrializadas a raíz del colapso financiero, acota y encarece las posibilidades del gobierno mexicano (y de otros países en desarrollo) y de las empresas privadas de contar con crédito de fuentes no oficiales. Esta restricción puede tener especial relevancia, en el caso mexicano, para las grandes empresas que se insertaron en los mercados mundiales apoyadas en el fondeo externo. Dado el clima recesivo mundial, es probable que en un corto plazo varias de estas empresas enfrenten dificultades para conseguir las divisas necesarias para cumplir con sus obligaciones crediticias, sea por pago de intereses o de capital. Tales situaciones pueden crear presiones puntuales pero significativas en el mercado cambiario mexicano. Recuérdese que al cierre de 2008, alrededor de 55\% del saldo de la deuda externa de México era del sector privado.

Ligado al tema anterior está el hecho de que desde hace ya 10 años gran parte del sistema bancario en México está compuesto por filiales — sumamente rentables - de grandes bancos internacionales, algunos de los cuales atraviesan situaciones críticas en sus balances. ¿Cuál será la estrategia que las centrales impondrán a sus filiales para enfrentar la crisis financiera? ¿En qué medida las operaciones de intermediación financiera de las filiales se verán presionadas para transferir más recursos al exterior? La respuesta a estas interrogantes está en el aire.

Para el gobierno mexicano, en su conjunto, el adverso panorama en el mercado mundial de capitales y el aumento en las primas de riesgo tienden a dificultar el acceso a fondos frescos del exterior. Esta situación puede orillar a cancelar proyectos de inversión que tengan alto contenido de divisas. Por otro lado, esta restricción puede, en alguna medida, aliviarse mediante una rápida respuesta de los organismos financieros internacionales o regionales. Al respecto, México se ha asegurado el acceso inmediato a una línea especial de financiamiento por parte del FMI de 30 mil millones de dólares, monto cercano a 35\% de las reservas internacionales con que cuenta, además del acuerdo con la FED por otro monto similar. 
Tanto la inversión extranjera directa como el ingreso neto de capital de corto plazo al país se verán afectados por la crisis financiera. La incertidumbre global, la caída en la demanda y las restricciones financieras desincentivan la IED en proyectos nuevos y en la ampliación o modernización de maquinaria en plantas existentes. De hecho, en 2008 la IED cayó 30\% y seguramente continuará cayendo en 2009. El capital de corto plazo puede sufrir oscilaciones bruscas en respuesta a presiones especulativas y la búsqueda de activos más seguros denominados en dólares, como los bonos del tesoro de EUA. Estos efectos de naturaleza financiera incidirán en la economía real, deprimiendo la actividad productiva y el empleo.

Finalmente, otra correa de transmisión es la que engloba los efectos multiplicadores que tienen las variaciones en el ingreso y en la capacidad de compra de grupos directamente afectados por la crisis sobre otros grupos inicialmente aislados del adverso shock externo inicial. Estos efectos hacen que a la primera ronda de debilitamiento o contracción de las exportaciones le acompañen otras rondas de efectos que deprimen el ingreso y empleo de sectores avocados a satisfacer el mercado interno. Un aspecto adicional a vigilar en esta iteración de efectos multiplicadores adversos es su impacto sobre los ingresos fiscales y, por ende, su repercusión sobre el gasto público. Al perder impulso el ingreso nacional se reduce la captación fiscal, reducción que adquiere proporciones mayores al perderse puestos de trabajo formales.

Es evidente que varios de estos efectos pueden acentuar las fragilidades estructurales de la economía nacional. Así, la crisis tiende a agravar la restricción de la balanza de pagos sobre el crecimiento de la economía mexicana. Igualmente, la necesidad urgente de instrumentar políticas fiscales compensatorias o contracíclicas para dar efectivo impulso a la economía nacional vuelve evidente la tan baja carga fiscal en el país y su dependencia de los ingresos petroleros. El impedimento legal que la federación ha impuesto a la ampliación del déficit fiscal público, en los hechos, seguramente se verá rebasado por la necesidad de usar la política de gasto público para evitar un deterioro económico y social mayor en las condiciones actuales. Con todo, la ley de responsabilidad presupuestaria, desde nuestro punto de vista, impide a la política fiscal reaccionar con la agilidad y la magnitud suficientes para responder a la emergencia nacional. Igualmente, la crisis evidenciará la debilidad y falta de profundidad del sistema de intermediación bancaria en México expresadas, en particular, en el insuficiente otorgamiento de créditos para fines productivos. 
Por otra parte, algunas de las fortalezas señaladas anteriormente cobran relevancia en la actual coyuntura. En efecto, haber dejado atrás las épocas de abultados déficit fiscales, excesivo endeudamiento externo y elevada inflación da la posibilidad de usar el gasto y el endeudamiento público para enfrentar la crisis sin forzosamente generar presiones críticas en la inflación o las finanzas públicas. Se abren espacios de política contracíclica a condición de que se adopte una actitud pragmática en la conducción de las finanzas públicas, alejada del dictum del presupuesto público equilibrado que sustenta la ley de responsabilidad presupuestaria.

Finalmente, en el terreno cambiario y monetario, el actual régimen de flotación, complementado por intervenciones directas selectivas del Banco de México en el mercado de divisas - y a diferencia de épocas previas o del caso de otras naciones en que la paridad cambiaria estaba virtualmente fija—, da pie a corregir rápidamente los precios relativos de los bienes comerciables y el precio de la divisa. Con ello, se ayuda a cortar corridas cambiarias especulativas y a proteger el empleo.

\section{REFLEXIONES FINALES}

Hoy en día, julio de 2009, el gobierno de México afirma adoptar una política económica dirigida a aminorar los efectos adversos de la crisis buscando no poner en riesgo los equilibrios fiscales logrados con las reformas neoliberales. Este objetivo, un tanto dual, abre retos críticos. Quizá el mayor sea el de precisar el margen de acción que tiene la política fiscal y monetaria para realizar una estrategia anticíclica sin poner en riesgo la solvencia fiscal y cambiaria de mediano y largo plazos. Es decir ¿qué tanto puede ampliarse el gasto o endeudamiento público sin detonar expectativas tan adversas en el mercado de capitales internacionales y entre las agencias calificadoras de riesgo que detonen corridas cambiarias en contra del peso mexicano, o bien provoquen una espiral insostenible de endeudamiento? ¿Cuánto exige hacerlo el deterioro del empleo?

La disyuntiva en su expresión extrema es dramática. Por un lado, el excederse en la prudencia fiscal y monetaria puede agravar los efectos adversos de la crisis internacional sobre el empleo, la producción y la pobreza entre la población mexicana. Por otro lado, incurrir en una expansión fiscal que sea realmente excesiva - o que sea percibida como tal por agentes clave — puede conducir a la insolvencia fiscal, repuntes agudos de la inflación y la inestabilidad cambiaria o financiera y una 
eventual crisis de balanza de pagos. Es no sólo un reto del gobierno el encontrar un justo medio en este dilema, es su obligación y compromiso.

Por lo pronto, cabe señalar que en vez de presentar una sola estrategia de repuesta a la crisis internacional desde sus inicios, el gobierno mexicano optó por anunciar una serie de programas e iniciativas que se han ido difundiendo y poniendo en operación de manera gradual. Una interpretación optimista es que ello permite responder de manera más flexible a la cambiante percepción que se ha ido teniendo de la magnitud de la crisis y de la fortaleza de la economía mexicana para resistirla. Una interpretación menos amigable de parte de diversos analistas apunta más bien a la falta de un adecuado diagnóstico de las causas, evolución e impacto del fenómeno externo. En este sentido, por ejemplo, se destaca que durante 2008 no se dio reducción alguna en las tasas de interés de referencia de la banca central ni se incurrió en déficit fiscal alguno. Fue hasta 2009 que las políticas fiscal, monetaria y cambiaria se orientan de manera contracíclica ante la crisis.

En todo caso, a la fecha, el gobierno federal ha anunciado la puesta en marcha de diversos programas de alcance nacional ante la crisis. Entre ellos destaca el Programa para Impulsar el Crecimiento y el Empleo (PICE) que se lanzó en octubre de 2008 y que comprende acciones en diferentes ámbitos: i) ampliación, reorientación y flexibilización del gasto público, sobre todo en infraestructura; ii) construcción de una refinería; iii) apoyo adicional a las pequeñas y medianas empresas, y iv) simplificación de trámites al comercio exterior y al establecimiento de empresas en el país. Poco después, en febrero, el presidente Calderón envió dos iniciativas de ley al Congreso de la Unión para modificar la ley del IMSS y del Instituto de Fomento a la Vivienda para que quienes pierdan su empleo formal tengan acceso más temprano, aunque acotado, a parte de su cuenta de retiro en Infonavit.

La proliferación de iniciativas es bienvenida en tanto refleje la creciente preocupación oficial por la crisis y la voluntad de orientar la política económica para hacerle frente. Según la Secretaría de Hacienda: "las medidas contracíclicas para 2009 incluidas en el PICE y el Acuerdo (...) implican un estímulo fiscal de $1.8 \%$ del PIB" (Reyes, 2009). Esta cifra, menor al monto correspondiente que, por ejemplo, el gobierno de China o el de Brasil están dedicando a los mismos fines, en el contexto mexicano refleja cierto compromiso con la reorientación contracíclica de la política macroeconómica. Sin embargo, desde esas declaraciones a la fecha se han implantado tres recortes extraordinarios al presupuesto público de 2009, el más reciente en julio 24. Ello, se argumentó, responde a la 
necesidad de ajustarse a las elevadas caídas de los ingresos tributarios en lo que va del año y las expectativas de aun mayores reducciones en 2010 por la baja en los recursos petroleros.

Un reto adicional surge de la oportunidad en la ejecución del gasto. Las disposiciones y normas en uso tienden a dificultar una rápida ejecución del gasto público, en particular en grandes programas de inversión, con el fin de asegurar su efectividad y eficacia. A estas limitaciones estructurales, se añaden en mayor o menor medida otras inherentes a la tendencia, ya de larga data, a reducir la participación del sector público en la inversión, lo que ha ido mermando o debilitando las áreas de diseño y ejecución de proyectos en diversas dependencias. Súmense a ello trabas ligadas a ineficiencias o a cuestiones políticas y se llega a una situación de mayores rezagos en la puesta en marcha de grandes proyectos de inversión. Tómese como ejemplo el abortado plan de construcción de un nuevo aeropuerto para la ciudad de México, proyecto que fue considerado como el de mayor envergadura para la administración del presidente Fox (2000-2006), o el rezago (ipor la falta de terrenos!) en iniciarla construcción de una nueva refinería. Aunque se aprobó, a la fecha sigue sin comenzarse.

En este contexto, es difícil precisar la magnitud final del programa fiscal que en realidad se pondrá a lo largo de 2009 para enfrentar la crisis, y no se diga de sus efectos. ¿En qué medida se complementarán por iniciativas de gasto o endeudamiento adicionales en el futuro cercano de profundizarse más la crisis económica o, por lo contrario, se verán contrarrestados por recortes adicionales en las erogaciones ante la creciente brecha fiscal o algún repunte de la inflación? El efecto de este programa sobre el nivel de actividad económica y el empleo es incierto. El presupuesto para 2009 será fundamental.

Desde nuestro punto de vista, es deseable que la orientación fiscal contracíclica se profundice. Para ello, se pueden aprovechar, por ejemplo, las posibilidades de financiar una ampliación del presupuesto fiscal mediante endeudamiento. Otra opción es la de incrementar una iniciativa de uso de recursos que sean erogados rápida y efectivamente para robustecer el empleo y proteger las condiciones de vida de los pobres. Al respecto, las cifras recientes del INEGI derivadas de las encuestas de hogares son preocupantes pues muestran un aumento significativo de la pobreza y de la desigualdad entre 2006 y 2008, es decir, antes de la crisis actual de 2009-2010 (Coneval, 2009). Un reto especial del gobierno mexicano será el de robustecer la política social para revertir este fenómeno. La magnitud de la tarea, sin embargo, rebasa la mera esfera de la política social. Coincidimos con el secretario ejecutivo del Consejo Nacional de Evaluación de 
la Política de Desarrollo Social (Coneval) cuando afirma: “...La mejor política social es el crecimiento económico que genere empleos y mejore los ingresos de la población, porque cuando la economía está mal el número de pobres crece, lo cual ya afecta a 50.6 millones de personas...”. O, en otras de sus afirmaciones: “...la ausencia de crecimiento económico vuelve muy difícil combatir de manera efectiva y sostenida la pobreza" (Enciso, 2009).

En las décadas recientes, las fases de bonanza en las economías latinoamericanas - entre ellas la mexicana - han sido detonadas por las mejoras abruptas y mayúsculas en los términos de intercambio, las exportaciones o las entradas masivas de capitales del exterior. ${ }^{2}$ Dichas bonanzas abren la oportunidad de contar con recursos extraordinarios — públicos o privados - para incrementar la inversión y el gasto social. Ello alivia algunas restricciones estructurales que frenan el desarrollo económico de largo plazo de las economías. El aprovechamiento juicioso de tales oportunidades ha sido más la excepción que la regla en la región. Así, tales flujos extraordinarios de recursos han terminado en numerosas ocasiones siendo malgastados, sin haber fortalecido la capacidad de crecimiento de largo plazo de nuestras economías. En contraposición, las épocas de crisis - detonadas por adversos y severos choques externos- revelan de manera drástica las limitaciones estructurales de nuestras economías. Entre ellas, destacan la restricción externa, la insuficiencia y la vulnerabilidad de los ingresos fiscales y la escasa profundidad del sistema de intermediación financiera. Todas ellas marcan la incapacidad de generar suficientes empleos de calidad para abatir la pobreza y la desigualdad.

Ojalá que el gobierno mexicano pueda efectivamente adoptar una estrategia fiscal y monetaria contracíclica de alcance suficientemente vasto para hacer frente a la crisis en el corto plazo, pero que la vez se acompañe de medidas de mediano y largo plazos que permitan contar con los ingresos fiscales necesarios y asegurar su uso eficiente, efectivo y transparente para el desarrollo económico y social de largo plazo. Para ello urge un nuevo pacto fiscal que amplíe sustancialmente los ingresos del sector público, reduzca su excesiva dependencia del petróleo y, a la vez, permita instrumentar un programa de inversión pública de largo aliento para ampliar la infraestructura y mejorar la educación del país.

Habrá que ver si la atención a los problemas urgentes de corto plazo se combina efectivamente con avances sustanciales hacia la eliminación de los obs-

${ }^{2}$ Siendo Pemex una empresa paraestatal, en el caso de México los ingresos petroleros engrosan significativa y directamente los recursos fiscales, lo que permite elevar el gasto público. 
táculos fundamentales que impiden el crecimiento elevado y sostenido de la economía mexicana en el largo plazo. En tal empeño, nos parece recomendable explorar las ventajas de abrogar la ley de responsabilidad presupuestaria a fin de adoptar una estrategia fiscal contracíclica como la de Chile, cuya política de gasto e ingreso público se fija en función de la tasa de expansión económica de largo plazo y no establece que el diferencial entre ingresos y gastos públicos deba ser igual a cero. Igualmente se recomienda la reanimación de las políticas de innovación y promoción industriales. Algunos de estos cambios requieren modificar las formas de interacción del Estado y el mercado en ciertos mercados clave de la economía mexicana, lo cual implica un análisis que rebasa el alcance del presente ensayo. 


\section{REFERENCIAS BIBLIOGRÁFICAS}

Banxico (2009), Informe sobre la Inflación, Banco de México, México, abril-junio. Comisión Económica para América Latina y el Caribe (CEPAL) (2008), Balance preliminar de las economías de América Latina y el Caribe 2008, LC/G.2401-P, Santiago de Chile.

Coneval (2009), "Pobreza por ingresos", http://www.coneval.gob.mx/coneval2/htmls/medicion_pobreza, Consejo Nacional de Evaluación de la Política de Desarrollo Social, México.

Economist Intelligence Unit (2009), “Mexico Country Report January 2009”, Londres, EIU. Enciso, Angélica (2009), "Coneval: hay programas sociales mal enfocados o dirigidos a ricos", entrevista a Gonzalo Hernández Licona, México, La Jornada, 24 de julio.

Este País (2009), "Entrevista con Jaime Serra Puche: La crisis y el mercado", Este País, México, núm. 215, p. 2.

Leyva, Jeanette, Rivelino Rueda, e Isabel Becerril (2009), "Lanza el Congreso propuestas de emergencia contra la crisis", México, El Universal, 19 de febrero de 2009.

Moreno-Brid, Juan Carlos (2001), "Essays on Economic Growth and the Balance-of-Payments Constraint, with Special Reference to the Case of México", disertación de doctorado, Reino Unido, Facultad de Economía y Política, Universidad de Cambridge.

- (2009), "La economía mexicana frente a la crisis internacional", Nueva Sociedad, núm. 220, marzo-abril.

— histórica", Revista de la Cepal, núm. 84, p. 12.

— $\mathrm{y}-(2009)$, Developement and Growth in the Mexican Economy: a Historical Perspective, Nueva York, Oxford University Press.

Reyes, Adriana (2009), “La crisis en la óptica de Carstens”, Ejecutivos de Finanzas, núm. 73. Reyes Heroles, Federico, y F. Suárez Dávila (2009), “Presentación de 'La crisis: testimonios y perspectivas"”, Este País, núm. 214, p. 1.

Secretaría de Hacienda y Crédito Público (SHCP) (2009a), Informe trimestral sobre la situación económica, las finanzas públicas y la deuda pública, cuarto trimestre de 2008, México.

— (2009b) Información de finanzas públicas y deuda pública, enero-diciembre de 2008, México.

Werner, Alejandro (2009), "Perspectivas económicas para 2009 y el Acuerdo Nacional en favor de la Economía Familiar y el Empleo", presentación ante la Comisión de Hacienda y Crédito Público de la Cámara de Diputados, 11 de febrero. 